\title{
Available measures counteraction of COVID-19 from experience of traditional medicine
}

\begin{abstract}
Ways of prevention and treatment of a SARS (viral respiratory infections), strengthening and increase in immunity are considered with we the apply medicine of the Wormwood bitter a grass (Artemisiae absinthii herba). This manuscript is a review of alternative methods to SARS. The authors are military experts who repeatedly had special medical training (paramedicine) for self-rescue and survival so they write about the use of Artemisiae absinthii, natural herba, to prevention and treatment of SARS. Availability of effective natural remedies is unprofitable to pharmaceutical corporations.
\end{abstract}

Keywords: prevention and treatment of a SARS (viral respiratory infections), increase in immunity, Artemisiae absinthii herba
Volume 9 Issue 3 - 202I

\author{
Petrov Sergey, ' Andrey Dolgan, ${ }^{2}$ Yury \\ Polishchuk $^{2}$ \\ 'Department of health \& safety, Moscow State Pedagogical \\ University, Russia \\ ${ }^{2}$ Department of health \& safety, International academy of \\ Sciences ecology and safety (St. Petersburg), Russia
}

Correspondence: Petrov Sergey, Department of health \&
safety, Moscow State Pedagogical University, Russia, Tel +7 90350787 46, Email svpetrov47@mail.ru

\section{Introduction}

In the conditions of fast emergence of new strains of viral infections the pharmaceutics always lags behind. It has negative effect on society mentality, causes a loss to economy and safety of any country. Even at emergence of a set of vaccines, it is impossible to vaccinate all at once, and vaccines aren't always effective to new mutations of coronavirus which will constantly change. Sometimes vaccination is contraindicated, is late or is inaccessible or is boycotted. In these conditions a real security measure from a SARS (viral respiratory infections) is strengthening of immunity that increases chances of everyone and helps to resist to new strains of corona viruses.

\section{Important help is use of the all-strengthening methods of traditional medicine confirmed with analyses}

Before the governments there is a problem of reliable supply of the population with the most plain available substances, clear techniques and technologies of propaganda for them. Authors of article are military experts who repeatedly had special medical training (paramedicine) for self-rescue and survival. They were influenced by different methods of strengthening of immunity at a SARS. Many know what at a SARS recommends to bring toxins which are emitted by a virus out of an organism and also to conduct the antioxidant therapy directed to normalization of processes in an organism. We drink more liquid: vitamins, fractional and healthy food, inhalation of spirit tinctures of onions and garlic. However many just don't observe the most available recommendations. The laziness captured mankind. The survival instinct through personal overcoming difficulties is reduced. Many wait for a magic tablet, and it is always late. In our personal practice the wormwood a bitter grass" was most effective ". At the getting fat and aging residents of the cities wormwood extracts (tea, syrup) improve work of a pancreas, release of pancreatic juice and bile. The wormwood strengthens metabolism and immunity due to improvement of processing of what we eat, and improvements of removal of the remains of food (slags). With age the pancreas (as well as other bodies) weakens, the long chain of gradual refusals of systems of an organism begins.
Pancreatitis on our illiteracy leads to the long list of indispositions. Many don't believe that the cheap and available grass, begins to help at dozens of diseases. Availability of effective natural remedies is unprofitable to pharmaceutical corporations. Their voices about inefficiency of a wormwood sound more loudly, than the description of a huge number of successful experiments. In an organism of city dwellers those substances (directly from a bed) which are received by the people living in rural areas chronically aren't enough. Each person applying tea with dried herbs from pharmacy has an opportunity to hold own safe testing by introspection and consultations with doctors. Use of a wormwood against Covid-19 is represented to us very relevant. Our offers are supported not only personal experience, but also in works of scientists which are given in the list of references. While in pharmacies there aren't enough reliable drugs our approach remains an effective alternative.

\section{Application of "a wormwood of a bitter grass" allowed authors to be protected from a SARS surely}

Wise men say: "You want a dolce vita - you eat and drink bitter. You want bitter life in diseases - consume a lot of sweet". In the period of spring and autumn epidemics of a SARS it is useful to accept (for prevention) rather small amount of this means in the form of additive in tea or coffee. And at emergence of obvious symptoms of a disease, we increase a dose of inclusion in 3-4 times for 5 - 7 days that helps an organism to mobilize the resources of fight. Then the break is necessary. Observation of our relatives is shown that the "wormwood" resource is effective for many. But everyone needs to consult with the attending physician to reveal individual contraindications and to observe the principle: "not to do much harm".

\section{"The bitter wormwood", several millennia at many people is considered "the health elixir"}

It is mentioned in papyruses of Ancient Egypt (1550) and in the Bible. The Latin name Artemisia is formed on behalf of the Ancient Greek Goddess Artemis - the patroness of all live on Earth. The wormwood on taste is very bitter, but these are only the first 5-6 days 
of reception. Later the taste of bitterness disappears, the organism will begin to perceive it as useful substance. The wormwood contains essential oil a part of which more than 90 substances are; organic acids; vitamins (B1, B2, B6, K, C, PP, carotene); proteins, starch, tannins, there are a lot of minerals, and biologically active agents and also absinthe. The bitter taste of "A bitter wormwood" is used for production of Vermouth and also Absinthe which was produced for the French army as dysentery and malaria medicine 200 years ago and also disinfectant for drinking water. From a wormwood and its components prepare also: jam and the gelatinized desserts, syrups which have positive impact on strengthening of human health. In some countries the crushed "Bitter wormwood" is used as seasoning instead of pepper, especially at consumption of greasy food (a turkey, a duck, a goose, etc.). "A wormwood bitter the grass" is included in the list of the medicinal in more than 20 countries. Official recommendations about use of medicines of "A bitter wormwood" fix only 2-3 leading effects that doesn't reflect all its properties and opportunities. Experience of the scientific of several countries proved efficiency of use of "A bitter wormwood" as anti-virus and anti-infectious means. Several states put into practice of the citizens since children's age the medical Covid-Organics syrup created on the basis of "Wormwood" at Malgashsky institute of applied researches (IMRA). (https://ria. $\mathrm{ru} / 20200427 / 1570605697 . \mathrm{html})$

Ways of preparation and application are described by us in the Russian magazine//Fundamentals of health and safety. Bases of safety of life. - No. 2 - 2020 - C.49. https://elibrary.ru/item.asp? id=440 I 3032 :

A. Crushing of a grass for reception in the form of grass meal.

B. Selection of florets for intake in a dry form.

C. Zavarivany herbs in boiled water for reception in the form of water solution.

The dosage (minimum or maximum) is defined depending on weight, age of the person (the advanced age is more than the weight, "the more spoon"). In the beginning it is necessary to take with caution, gradually increasing a dose. It is important to understand that there are no negative feelings (bitterness isn't counted), which signal about contraindications to application of this means. On all questions it is necessary to consult with the attending physician.

I. For prevention: Our personal dosage of "grass meal" - 3 times a day on $1 / 6$ or $1 / 3$ teaspoons (depending on health).

II. At emergence of symptoms of a SARS: I accept already 4-5 times a day on $1 / 2$ teaspoon of "grass meal".

III. Preparation of "grass meal": the grass needs to be crushed previously (for example, in the coffee grinder) and then to mix the processed grass with water (tea, juice), to a condition of gruel and to accept, washing down with water or tea. It is necessary in order that powder didn't get into airways. Stocks can be poured out in a jar with a cover and to store in the dark place.

IV. In the form of "grass meal: The bitter wormwood" is used as seasoning in food as pepper or salt at meal time in volume of 1 - 2 pinches.

V. In the form of "oil infusion" which is prepared by insisting of "grass meal" or a fresh grass of "A bitter wormwood" within 10 days in linseed, olive, corn or sunflower unrefined oil and then it is filtered and used at meal time in the amount of about $1-2$ teaspoons depending on concentration of infusion.
"Bitter a grass" for strengthening of immunity it is useful for wormwood to accept medicine daily in small amounts (especially to the people having liver diseases). At reception it is important to observe a dosage, to take with caution, analyzing the reactions and feelings. We recommend to keep daily records. "The bitter wormwood" at pregnancy and feeding of the child is contraindicated the milk and also when there is an allergy to her. Patients with asthma and children up to 14 years need to accept a wormwood with the increased care and only under observation of the doctor. It is important to use enough clean drinking water - not less than 1 - 2 liters a day for a conclusion from an organism of unnecessary and hazardous substances at activization of work of a pancreas. Time of application of high doses (more than 10 - 15gp. in day) shouldn't exceed one month then it is necessary to take a break on one - three weeks and then intake of this medicine it is possible to renew, analyzing the feelings and results together with the doctor.

\section{Other means for strengthening of immunity in the period of epidemics}

\section{Vitamins and dietary supplements}

a) Ascorbic acid. It is possible to replace it with broth (syrup) of a dog rose, to use a natural lemon, orange, grapefruit, but in the sum no more than $1 \mathrm{mg}$. $\mathrm{C}$ vitamin in day.

b) Komplivit or Selmevit an intensive course - 1 tab. a day.

c) Iodine an asset - 1-2tab. a day.

d) Kapilar - 1-2 tab. a day.

\section{Animal and/or vegetable fats}

The fat piece with garlic eaten during a season of epidemics will help to strengthen immunity. Lard in any kind, including: salty, smoked and boiled, etc. (dosage: $30-90 \mathrm{rp}$. / in day). Fat one of the few products containing arachidonic acid which is a source of protective proteinaceous structures in a human body and interferes with cholesterol adjournment. Fat is necessary for normal work of lungs. Fat almost completely consists of related to our organism of saturated and nonsaturated fatty acids - construction material of cellular membranes (it contains up to $40 \%$ of polyunsaturated fatty acids, almost like red fish). The creamy and/or vegetable oil which isn't refined without heating, including: linen, olive, corn, sunflower, cod-liver oil (dosage: $1-6$ teaspoons / in day). The called fats are useful to protection of lungs. Each alveolus (smallest working unit of lungs in which there is a gas exchange) is covered with "lubricant" substance - surfactant which doesn't allow an alveolus to be stuck together at an exhalation. Surfactant has the difficult chemical composition, but $90 \%$ of this substance make fats. And oil just fills their stock.

1. Oats in the form of porridge porridge (100-300гр. in day). Oats as a ginseng, he contains many biologically active vitamins and mineral substances. WHO is recommended by oats as equivalent replacement of proteins of meat, milk and eggs. Oats apply as the all-strengthening means at an anemia, physical, intellectual and nervous exhaustion, at the bronchitis, pneumonia and other diseases which are followed by cough. It is useful to apply oats decoctions at metabolic disorders, viral hepatitis, gastritises, the enterokolitakh, stomach ulcer of a stomach and a duodenum, during recovery and rehabilitation.

2. The natural juice, vegetables and fruit recommended by the doctor as not all from them are equally useful. Those that dilute 
blood are especially useful, strengthen the blood-groove which weakened over the years. Some give heartburn, others provoke hypostases. To specify these details and also a dosage it is possible at doctors and in network.

3. Sour-milk products: kefir, yogurt, ayran, koumiss, cottage cheese, sour cream, etc., in coordination with the doctor. There are grades of very strong or salty cheese which are useful not to all. Though in small doses and with porridge the harm is minimized. As a rule, the observant consumer by 40 years already well knows from what products at him there comes the weakness and discomfort, and from what cheerfulness and inflow of forces. What products are compatible to him and among themselves and what aren't compatible.

\section{Other measures for strengthening of immunity}

The positive spirit - at people regeneration in an organism happens to good mood quicker (at soldiers of the winning army of a wound heal quicker, than the same wounds at soldiers of the defeated army). Healthy lifestyle. According to scientists the human health depends for $20 \%$ of heredity; for $10 \%$ of development of health care; for $20 \%$ of ecology for $50 \%$ of a way of life of the person. Observance of rules of healthy food; exercises; refusal of addictions; observance of a day regimen and healthy sleep ( $7-10$ hours a day in one and too time); hardening of an organism (bathing, bath, contrast shower); intake of necessary vitamins and mineral substances; respect for hygiene; maintaining mental health (positive thinking); use of pure enough, favorable environment (air, silence etc.).

\section{Conclusions and offers}

By means of the officinal herbs and other folk remedies checked and approved by medicine it is possible to reduce mortality and to economically solve some problems of prevention and treatment of a SARS, more effective new medicines and protocols of their application won't appear yet. Everyone can check the above-mentioned methods of strengthening of immunity and protection against a SARS under control of the doctor to understand their individual efficiency.
Strengthening of immunity available means is the important line of defense in some regions, along with vaccination. ${ }^{1-9}$

\section{Acknowledgments}

None.

\section{Conflicts of interest}

The authors declare that there is no conflict of interest.

\section{References}

1. Manuylov BM. Wormwood treatment. Bud Zdorov magazine. 2002;8(110):56-58.

2. Pharmacopoeian article (Russian Ministry of Health) of the Wormwood bitter grass. Фармакопея.pф Pharmacopoeia.

3. Berezovskaya TP, Amelchenko VP. Wormwood of Siberia: systematization, ecology, chemistry, a hemo sistematika, the prospects of use / - Novosibirsk: "Science" Siberian office; 1991:125.

4. Khanin MA. New data on the chemical composition of Artemisia absinthium L. essential oil of the Siberian flora. Chemistry of vegetable raw materials. 2000;3:33-40.

5. Karomatov ID, Kakhorova SIK. A herb a wormwood bitter - the chemical composition, medicinal properties. Biology and integrative medicine. 2018.

6. Kartashova OL, Tkachyov AV. Influence of essential oils of a wormwood on growth of microorganisms and formation of biofilms by them. Bulletin of the Orenburg scientific center OURO RAHN; 2012.

7. Utkina TM. Antimicrobic and anti-persistent effect of plant extracts of different types of a wormwood of Southern Siberia. OURO RAHN, Orenburg. 2014.

8. Platonov VV. Chemical composition of organic matter of a wormwood bitter (artemisia absenthum 1., family of a thistle family). Messenger of new medical technologies. 2019(5).

9. Severin AP, Siplivaya LE, V Ya Yatsyuk. Immunometabolic efficiency of complexes of meal of a wormwood bitter (artemisia absinthium 1.) at a staphylococcal infection. Scientific sheets of the Belgorod State University Medicine Pharmacy; 2012. 